\title{
CAPITULO 48: PREVALÊNCIA DE Listeria spp. E Listeria monocytogenes EM QUEIJO ARTESANAL DO MEIO-OESTE CATARINENSE
}

\section{CHAPTER 48: PREVALENCE OF Listeria spp. AND Listeria monocytogenes IN ARTISANAL CHEESE FROM SANTA CATARINA MIDWEST}

\author{
Bruna Marchesan Maran ${ }^{1}$; Thalia Indara Balsan ${ }^{2}$; Nei Fronza ${ }^{3}$; Silvani Verruck ${ }^{4}$; Sheila Mello da Silveira ${ }^{5}$
}

\begin{abstract}
Resumo
A ocorrência de doenças veiculadas por alimentos é cada vez mais frequente, atingindo um número crescente de indivíduos. Os surtos ocasionados por Listeria monocytogenes têm sido associados a uma ampla gama de produtos alimentícios incluindo derivados lácteos. Muitas especialidades regionais de queijo são fabricadas a partir de leite cru nas propriedades rurais, empregando barreiras tecnológicas numa base empírica, podendo representar risco à segurança do consumidor se patógenos estiverem presentes. O objetivo deste trabalho foi determinar a prevalência de Listeria spp. e L. monocytogenes isoladas de amostras de queijo artesanal coletados no município de Seara, Estado de Santa Catarina, Brasil. Foram analisadas 8 amostras de queijo artesanal, sendo realizadas as etapas de enriquecimento primário e secundário, seguidas do plaqueamento em meios de cultura seletivos. As colônias suspeitas de Listeria spp. ou L. monocytogenes foram testadas quanto às características fenotípicas de crescimento em Agar Listeria segundo Ottaviani e Agosti, hemólise, utilização de carboidratos, reação da catalase, coloração de Gram, teste VM-VP, redução de nitrito e motilidade. Nenhuma amostra apresentou presença do patógeno L. monocytogenes, mas houve presença do gênero Listeria spp. em quatro amostras de queijo artesanal, fazendo-se necessário o contínuo monitoramento do rebanho e da qualidade microbiológica do alimento.
\end{abstract}

Palavras-Chave: queijo artesanal, leite cru, listeriose.

\begin{abstract}
The occurrence of foodborne diseases is more and more frequent, affecting an increasing number of individuals. Outbreaks caused by Listeria monocytogenes have been associated with a wide range of food products including dairy products. Many regional cheese specialties are made from raw milk on rural properties, employing technological barriers on an empirical basis, which can pose a threat to consumer safety when transmitting pathogens. Therefore, the objective of this study was to determine the prevalence of Listeria spp. and L. monocytogenes isolated from artisanal cheese samples collected in the municipality of Seara, State of Santa Catarina, Brazil. Eight artisanal cheese samples were analyzed, with the primary and secondary enrichment stages being performed, followed by plating in selective culture media. The suspected colonies of Listeria spp. or L. monocytogenes were tested for phenotypic growth characteristics on Agar Listeria according to Ottaviani and Agosti, haemolysis, use of carbohydrates, catalase reaction, Gram coloring, VM-VP test, nitrite reduction, and motility. No sample had the presence of the pathogen L. monocytogenes, but there was the presence of the genus Listeria spp. in four samples of artisanal cheese, making it necessary to monitor the herd and the microbiological quality of the food continuously.
\end{abstract}

\footnotetext{
${ }^{1}$ Engenharia de Alimentos, Universidade Federal de Santa Catarina, bruna.maran@ gmail.com

${ }^{2}$ Engenharia de Alimentos, Instituto Federal Catarinense - Campus Concórdia, thalia.balsan@ gmail.com

${ }^{3}$ Prof. Dr., Instituto Federal Catarinense - Campus Concórdia, nei.fronza@ifc.edu.br

${ }^{4}$ Profa. Dra., Universidade Federal de Santa Catarina, silvani.verruck@ufsc.br

${ }^{5}$ Profa. Dra., Instituto Federal Catarinense - Campus Concórdia, sheila.silveira@ifc.edu.br
} 
Keywords: artisanal cheese, raw milk, listeriosis.

\section{Introdução}

Doenças veiculadas por alimentos (DVA's) são doenças ocasionadas pela ingestão de alimentos contaminados por bactérias, vírus, parasitas infecciosos, fungos, entre outros (HOFFMANN; SCALLAN, 2017). Dentre os microrganismos considerados patógenos de origem alimentar, podemos citar: Salmonella spp., Campylobacter spp., Escherichia coli, Listeria monocytogenes, Yersinia enterocolitica, Staphylococcus spp., Clostridium perfringens, entre outros, os quais são responsáveis por parte das morbidades e mortalidades, resultando em danos significativos ao desenvolvimento socioeconômico em todo o mundo (OMS, 2015; WIWANITKIT, 2018).

Segundo a Organização Mundial da Saúde (OMS), em 2010 ocorreram 600 milhões de casos e cerca de 420 mil mortes causadas por doenças veiculadas por alimentos no mundo, tomando como base 31 agentes de risco de contaminação (OMS, 2015). Já nos Estados Unidos, conforme relatório realizado em dez Estados do País pela The Foodborne Diseases Active Surveillance Network, no ano de 2019 ocorreram 25.866 infecções e 122 mortes provenientes de doenças veiculadas por alimentos. Destes casos, os ocasionados por contaminação por Listeria monocytogenes foram 134 infecções, com índice de hospitalizações de $98 \%$ e taxa de letalidade de $16 \%$, podendo ser considerada um constante problema de saúde pública devido principalmente a sua alta mortalidade (CDC, 2020).

Listeria spp. são bactérias Gram-positivas em forma de bastonete curto ou cocobacilo, não esporuladas e que podem ser aeróbicas ou anaeróbicas facultativas. Dentre as 10 espécies do gênero Listeria, pode-se destacar a L. monocytogenes como espécie patogênica para os seres humanos (THAKUR; ASRANI; PATIAL, 2018). Essas são anaeróbias facultativas, fermentadoras de glicose sem produção de gás e têm crescimento ideal a $37^{\circ} \mathrm{C}$, mas são capazes de crescer em uma ampla faixa de temperatura entre 0 e $45^{\circ} \mathrm{C}$. Possui resistência ao cloreto de sódio e cresce em pH entre 4,6 a 9,2 (REES; DOYLE; TAYLOR, 2017). Outras características que podem diferenciá-la de outros microrganismos estão apresentadas na Tabela 1, as quais fazem parte dos testes bioquímicos realizados para identificação de L. monocytogenes (RYSER; DONNELLY, 2015). 
Tabela 1. Características de Listeria monocytogenes

\begin{tabular}{ll}
\hline Característica & Resultado \\
\hline Motilidade guarda-chuva & + \\
Produção de catalase & + \\
$\beta$-Hemolise & + \\
L- Ramnose & + \\
D-Xilose & - \\
Oxidase & -
\end{tabular}

Fonte: Adaptado de Ryser, Donnelly (2015).

A espécie Listeria monocytogenes é causadora de dois tipos de listeriose em seres humanos, a do tipo invasiva e a não invasiva. A listeriose não invasiva ou gastrointestinal não é diagnosticada com frequência e ocorre geralmente em adultos saudáveis, provocando febre e diarreia. Já a listeriose invasiva ocorre geralmente em pessoas mais suscetíveis como neonatos, gestantes, indivíduos com 65 anos ou mais e indivíduos imunocomprometidos, atuando em cada grupo de pessoas de maneira distinta (DESAI; TRIMBLE, 2019).

O patógeno causador de listeriose pode ser isolado de fontes ambientais como solo e água, trato gastrointestinal de bovinos, coelhos, peixes, aves, humanos e outros, além de diversos alimentos tais como leite cru, carne crua, queijos moles, peixes, aves, frutos do mar, frutas, vegetais e outros produtos minimamente processados ou prontos para o consumo. Essa contaminação em alimentos pode ser resultado de possíveis más condições de manuseio e processamento do alimento, uma vez que o patógeno pode resistir a temperaturas de congelamento e falhas na pasteurização (THAKUR; ASRANI; PATIAL, 2018).

Como a L. monocytogenes está presente no solo, pastagens e água, as fazendas de gado leiteiro tornam-se um ambiente natural para esta bactéria que, por consequência, pode estar presente no trato gastrointestinal dos animais. Dessa forma, para evitar a contaminação cruzada entre o ambiente do rebanho e a sala de ordenha para o leite cru, é necessária a implantação de medidas para impedir a colonização do ambiente de obtenção e processamento de leites e derivados e impedir a contaminação pós-processamento de produtos lácteos (FOX; JIANG; GOBIUS, 2018).

Em alguns países da América Latina há muitos queijos produzidos de maneira artesanal que são geralmente fabricados em instalações pequenas próximas da fazenda e que, muitas vezes, carecem de medidas de higienizações eficazes e do controle microbiológico do leite utilizado na produção de derivados (BARRÍA et al., 2020). Devido a esses e outros fatores, muitos queijos de curta maturação de origem latino-americana estão associados a surtos de origem alimentar (GÉRARD et al., 2020). No Brasil, não há relatos de surtos de listeriose 
humana provocados por alimentos, no entanto os casos ocorridos no país ainda são subdiagnosticados e subnotificados (BARANCELLI et al., 2014).

O setor de laticínios tem grande importância econômica no Brasil, sendo que em 2014 foram produzidos 1.032.000 toneladas de queijo baseada principalmente em pequenas e médias indústrias (CRUZ et al, 2016; OXARAN et al., 2017). Porém, o processo de produção de queijo é bastante diversificado e, além da produção industrial, há também a produção de forma artesanal que, por sua vez, pode apresentar-se como a principal fonte de renda de pequenos produtores rurais (CORREIA; ASSIS, 2017).

Os queijos artesanais brasileiros são aqueles elaborados por métodos tradicionais que possuem vinculação e valorização territorial, regional ou cultural e que respeitam os protocolos de elaboração estabelecidos para cada variedade (BRASIL, 2019). Existem muitas variedades de queijos tradicionais de cada região tais como o queijo Marajó produzido na ilha do Marajó no norte do País, os queijos requeijão e manteiga do nordeste, Araxá, Campo das Vertentes, Canastra, Cerrado, Serro e Triângulo Mineiro tradicionais do Estado de Minas Gerais e queijo Serrano e colonial característicos do Sul do Brasil (KAMIMURA et al., 2019).

No Estado de Santa Catarina, a produção de queijo artesanal, conforme o censo agrícola brasileiro de 2017, foi estimada em 8.210 toneladas por ano (CARVALHO et al., 2019). E, em 2019, o Decreto ${ }^{\circ} 362$ regulamentou a Lei ${ }^{\circ} 17486$ de 2018 que dispõe sobre a produção e comercialização de queijos artesanais de leite cru no Estado (SANTA CATARINA, 2018, 2019). O leite cru para elaboração do queijo deve ser recém-ordenhado da própria fazenda ou de outras propriedades próximas, desde que atendam todas as normas técnicas sanitárias, para depois ser beneficiado por meio de métodos tradicionais que mantenham as características históricas-culturais e regionais, utilizando mão de obra predominantemente familiar e respeitando as boas práticas de fabricação com a garantia da segurança alimentar (SANTA CATARINA, 2019). Todavia, os queijos produzidos a partir de leite cru podem apresentar maiores ocorrências de contaminação por Listeria, principalmente em produtos com umidade de alta a média, tornando-se um desafio para a segurança de alimentos (SANTOS, 2016). Sendo assim, o objetivo deste trabalho foi determinar a prevalência de Listeria spp. e Listeria monocytogenes isoladas de amostras de queijo artesanal coletadas no município de Seara, Santa Catarina. 


\section{Material e Métodos}

Área de Estudo

As propriedades rurais que participaram do projeto pertencem ao município de Seara pertencente a região do meio oeste de Santa Catarina (Figura 1) e foram definidas em conjunto com a EPAGRI (Empresa de Pesquisa Agropecuária e Extensão Rural de Santa Catarina) e Crediseara. Para este estudo, foram utilizadas 8 amostras de queijos artesanais. As amostras de queijo artesanal foram coletadas assepticamente em frascos e embalagens estéreis, acondicionadas em caixas isotérmicas e transportadas ao Laboratório de Microbiologia de Alimentos pela EPAGRI para a realização das análises microbiológicas.

Figura 1. Localização do município de Seara no Estado de Santa Catarina, Brasil.

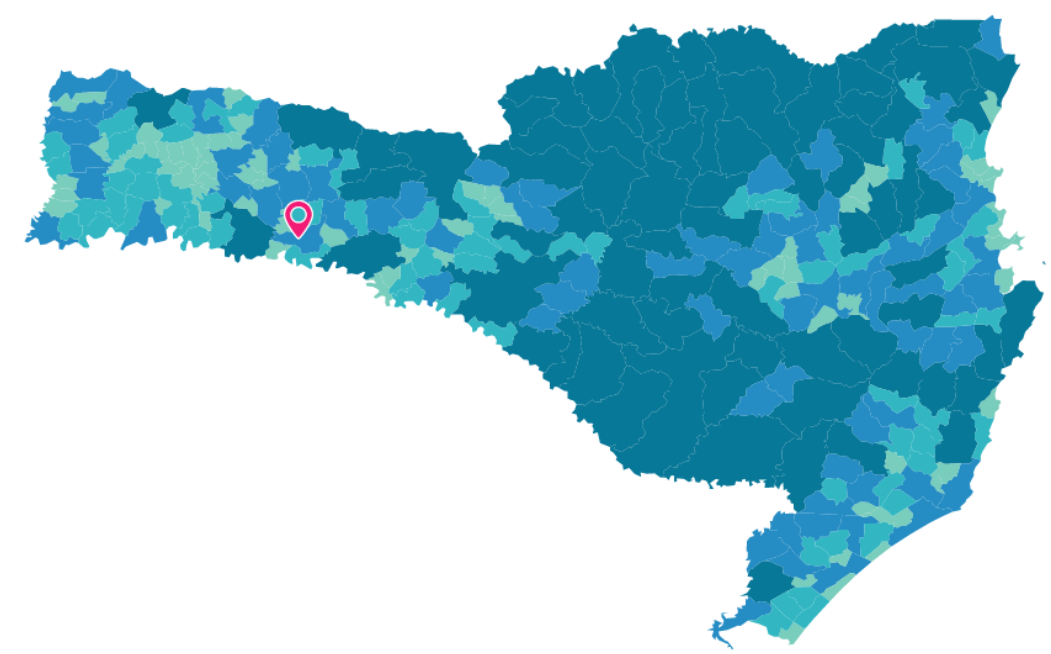

Fonte: IBGE (2019).

\section{Análise Microbiológica}

\section{Pré-enriquecimento das amostras}

O pré-enriquecimento da amostra foi realizado utilizando-se caldo UVM de enriquecimento para Listeria, incubado a $30{ }^{\circ} \mathrm{C}$ por 24 horas. Para o enriquecimento seletivo, a partir do meio de pré-enriquecimento, foi inoculado o caldo Fraser, suplementando-o conforme a indicação do fabricante e também incubado a $30^{\circ} \mathrm{C}$ por 24 a 48 horas (BRASIL, 2003).

\section{Identificação}

A partir do enriquecimento secundário com o caldo Fraser, inoculou-se, com o auxílio da alça de platina, a superfície dos meios sólidos ágar ALOA sem suplemento, ágar Oxford (AO) e ágar Palcam (AP). Então incubou-se as placas de Petri invertidas a $37^{\circ} \mathrm{C}$ por 24 e 48 horas. Repetiu-se o procedimento acima do primeiro meio sólido para o segundo meio de 
enriquecimento sólido, ALOA, incubando-o as placas invertidas a $37^{\circ} \mathrm{C}$ por $24 \mathrm{~h} \pm 2 \mathrm{~h}$. Para o ágar ALOA, considerou-se como presuntivo positivo para Listeria monocytogenes as colônias verde-azuladas cercadas por um halo opaco e Listeria spp. positivo as colônias verde-azuladas com ou sem halo opaco (ISO, 2017).

\section{Seleção de colônias para confirmação}

Selecionou-se colônias de cada placa presumida como Listeria monocytogenes ou Listeria spp. estriando-as em placas de ágar nutriente pré-secas permitindo o desenvolvimento de colônias isoladas. Incubou-se as placas a $36^{\circ} \mathrm{C} \pm 1^{\circ} \mathrm{C}$ por $24 \mathrm{~h}$ e então realizou-se os testes de confirmação para Listeria spp. e Listeria monocytogenes. Caso a primeira colônia fosse negativa, utilizou-se até 5 colônias de cada placa de meio seletivo para análise (ISO, 2017).

\section{Teste de hemólise em ágar sangue}

Selecionou-se com o auxílio de alça de platina colônias com características morfológicas e fisiológicas indicativas de Listeria spp. e também amostra controle de $L$. monocytogenes e inoculou-as em placas com meio ágar-sangue sólido. Incubou-se as placas a $37^{\circ} \mathrm{C}$ por $24 \mathrm{~h}$ e $\operatorname{logo}$ após examinou-se as cepas de teste e amostras controles de $L$. monocytogenes (ISO, 2017).

\section{Utilização de carboidratos}

Para a preparação do caldo de L-Ramnose e D-Xilose preparou-se anteriormente a base e a solução do carboidrato. A base é composta por $10 \mathrm{~g}$ de digesto enzimático de tecidos animais, $1 \mathrm{~g}$ de extrato de carne, $5 \mathrm{~g}$ de cloreto de sódio, $0,02 \mathrm{~g}$ de púrpura de bromocresol $1000 \mathrm{~mL}$ de água. Dissolveu-se os componentes em água e corrigiu-se o $\mathrm{pH}$ para $6,8 \pm 0,2$ a $25^{\circ} \mathrm{C}$. Então esterilizou-se em autoclave por $15 \mathrm{~min}$ a $121^{\circ} \mathrm{C}$. Para cada uma das soluções de carboidratos, D-Xilose e L-Ramnose, utilizou-se $100 \mathrm{~mL}$ de água e $5 \mathrm{~g}$ de carboidrato, passando-os pela esterilização por filtração em membrana de $0,45 \mu \mathrm{m}$. Então, preparou-se assepticamente os tubos de ensaio com 1mL de solução do carboidrato e 9mL de base (ISO, 2017).

Selecionou-se colônias típicas de Listeria spp. a partir do ágar nutriente e inoculou-as em cada um dos caldos, incubando a $37^{\circ} \mathrm{C}$ por 5 dias. Realizou-se o mesmo procedimento para a amostra controle positiva de L. monocytogenes. Para a reação positiva observou-se a formação de ácido indicado pela coloração amarela para ambos os carboidratos (ISO, 2017). 


\section{Reação de catalase}

Suspendeu-se uma colônia isolada no ágar nutriente em uma gota de solução de peróxido de hidrogênio 3\% em uma lâmina. Observou-se a formação ou não formação imediata de bolhas de gás. O aparecimento de bolhas de gás indica uma reação catalase positiva (ISO, 2017).

\section{Coloração de Gram}

A técnica de coloração de Gram foi realizada de acordo com a ISO 721. Selecionou-se as colônias obtidas no ágar nutriente e inoculou-se as mesmas em tubos com meio líquido nutritivo não seletivo. Incubou-se a $25^{\circ} \mathrm{C}$ de 8 a $24 \mathrm{~h}$ até que o meio ficasse turvo. Com o auxílio de alça de platina previamente esterilizada, obteve-se uma porção do caldo turvo e depositouse sob uma lâmina limpa. Então, realizou-se, com o auxílio de outra lâmina a $45^{\circ}$ sob a primeira, a técnica de esfregaço passando posteriormente pela fixação em chama. Cobriu-se o esfregaço com solução cristal violeta deixando-se agir por $1 \mathrm{~min}$. Passado o tempo, enxaguou-se suavemente a lâmina inclinada com água destilada por alguns segundos. Cobriu-se a lâmina com a solução de iodo e deixou-se agir por 1min para lavar novamente a lâmina inclinada com água destilada por alguns segundos. Despejou-se então suavemente e continuamente uma película de etanol $95 \%$ na lâmina inclinada durante 30s. Enxaguou-se suavemente a lâmina inclinada com água para eliminar o etanol, cobriu-se a lâmina com safranina por 40s e enxaguou-se suavemente a lâmina inclinada com água deixando a lâmina secar (ISO, 2019).

Analisou-se a lâmina sob a objetiva de imersão de alta potência de um microscópio onde as células bacterianas que aparecem azul ou violeta são denominadas de Gram-positivas e aquelas que são coradas de rosa escuro a vermelho são denominadas de Gram-negativas (ISO, 2019).

\section{Teste de Vermelho de Metila e Vogues Proskauer (VM-VP)}

Usando a alça de platina, inoculou-se o tubo contendo $5 \mathrm{~mL}$ do meio VMVP previamente estéril e incubou-se a $37^{\circ} \mathrm{C}$ por $48 \mathrm{~h}$. Após a incubação, pipetou-se $1 \mathrm{~mL}$ do tubo incubado para outro tubo onde adicionou-se $0,6 \mathrm{~mL}$ de solução de $\alpha$-naftol a $5 \%$ e $0,2 \mathrm{~mL}$ de solução de hidróxido de potássio a 40\%. Agitou-se bem e inclinou-se o tubo deixando agir por $15 \mathrm{~min}$ a $1 \mathrm{~h}$ examinando a coloração. Se a coloração do tubo ficasse vermelha forte indicaria que a reação era positiva. Listeria spp. é positiva para VP. Caso a coloração permanecesse da cor do reagente (amarelo ou esverdeado) o teste era negativo. Reincubou-se a cultura remanescente no caldo VM-VP por mais $24 \mathrm{~h}$ e realizou-se o teste VM. Adicionou-se a $2,5 \mathrm{~mL}$ da cultura cinco gotas 
de vermelho de metila e observou-se imediatamente a coloração do meio, que se ficasse vermelha indicaria teste positivo, e se amarela, teste negativo (BRASIL, 2003).

\section{Redução do nitrato}

Inoculou-se $5 \mathrm{~mL}$ de caldo previamente preparado e estéril com uma alçada da cultura a ser analisada e incubou-se a $35^{\circ} \mathrm{C}$ por $24 \mathrm{~h}$. Logo após a incubação, adicionou-se $0,25 \mathrm{~mL}$ de reagente $\mathrm{A}$ (solução $0,8 \%$ de ácido sulfúrico) e $0,25 \mathrm{~mL}$ de reagente $\mathrm{B}$ para cada cultura. Em no máximo 10 minutos, observou-se a presença de coloração rósea avermelhada como teste positivo, indicando que o nitrato foi reduzido a nitrito. Diante de resultado negativo, adicionouse uma pitada de pó de zinco e deixou-se agir por 10 minutos. Então, observou-se se a cor permaneceu inalterada (teste positivo), ou se adquiriu coloração rósea avermelhada, indicando teste negativo para redução de nitrato (BRASIL, 2003).

\section{Motilidade}

Com o auxílio de uma agulha de inoculação previamente estéril, selecionou-se uma colônia típica de Listeria spp. da placa contendo ágar nutriente e inoculou-a no tubo contendo ágar motilidade previamente preparado e esterilizado. Incubou-se o tubo a $25^{\circ} \mathrm{C}$ por $48 \mathrm{~h}$. Após a inoculação, examinou-se o crescimento em torno do local onde foi inoculada a cultura suspeita e observou-se se ocorreu padrão típico de crescimento semelhante ao de guarda-chuva. Caso o crescimento não fosse suficiente, incubava-se por mais 5 dias, observando novamente após este tempo (ISO, 2017).

\section{Resultados e Discussão}

Dentre as oito amostras de queijo artesanal analisadas, apenas quatro apresentaram colônias típicas de Listeria spp. e/ou Listeria monocytogenes no ágar ALOA, Palcam ou Oxford. Desta forma, as colônias bacterianas suspeitas foram testadas quanto às características fenotípicas de crescimento em ágar ALOA, ágar sangue, utilização de carboidratos, reação da catalase, coloração de Gram, teste VM-VP, redução de nitrito e motilidade com resultados apresentados na Tabela 2. 
MARAN, et al.

Tabela 2. Análise das características fenotípicas das colônias suspeitas de Listeria spp. e L. monocytogenes em queijo artesanal.

\begin{tabular}{|c|c|c|c|c|c|c|c|c|c|c|c|c|}
\hline \multirow{2}{*}{ Amostra } & \multirow{2}{*}{$\begin{array}{c}\text { Ágar de } \\
\text { isolamento }\end{array}$} & \multicolumn{2}{|c|}{ ALOA } & \multirow{2}{*}{ Hemólise } & \multirow{2}{*}{ Xilose } & \multirow{2}{*}{ Ramnose } & \multirow{2}{*}{ Catalase } & \multirow{2}{*}{ Gram } & \multirow{2}{*}{$\mathbf{V M}$} & \multirow{2}{*}{$\mathbf{V P}$} & \multirow{2}{*}{ Nitrato } & \multirow{2}{*}{ Motilidade } \\
\hline & & $24 h$ & $48 h$ & & & & & & & & & \\
\hline $\mathrm{CP}$ & & \multicolumn{2}{|c|}{ + L. monocytogenes } & + & - & + & + & Cocobacilo G+ & + & + & - & - \\
\hline A1 & Palcam & + L. spp. & + L. spp. & Fraca & + & + & + & Cocobacilo G+ & + & - & - & - \\
\hline \multirow[t]{2}{*}{ A4 } & Palcam & - & + L. spp. & - & + & + & + & Cocobacilo G+ & + & + & - & - \\
\hline & $\mathrm{ALOA}^{*}$ & - & - & - & & & + & Cocobacilo G+ & - & - & - & - \\
\hline \multirow[t]{3}{*}{ A5 } & $\mathrm{ALOA}^{*}$ & - & + L. spp. & - & - & - & + & Cocobacilo G+ & - & - & - & - \\
\hline & Oxford & - & + L. spp. & - & + & - & + & Cocobacilo G+ & - & - & - & - \\
\hline & Palcam & + L. spp. & + L. spp. & Fraca & + & + & + & Cocobacilo G+ & + & + & - & - \\
\hline \multirow[t]{3}{*}{ A7 } & ALOA* & - & + L. spp. & - & + & - & + & Cocobacilo G+ & - & - & - & - \\
\hline & Oxford & - & + L. spp & - & - & - & + & Cocobacilo G+ & - & - & - & - \\
\hline & Palcam & - & + L. spp. & - & - & - & + & Cocobacilo G+ & - & - & - & - \\
\hline
\end{tabular}

CP: controle positivo. +L. spp.: positivo para Listeria spp.. A1, A4, A5, A7: amostras de queijo colonial. *Ágar base para ALOA sem suplemento. 
Para o meio cromogênico, seletivo e diferencial ALOA, foram identificadas no tempo de $24 \mathrm{~h}$ apenas o crescimento de colônias típicas de Listeria spp. em duas amostras (A1 e A5, ambas incubadas inicialmente no meio Palcam). Em 48h apenas a amostra A4 incubada inicialmente com ALOA não apresentou colônias típicas de Listeria spp., resultando em presuntivo negativo. Todas as demais amostras de queijo apresentaram-se com colônias típicas de Listeria spp. com coloração verde-azulada sem a presença de halo opaco, sendo o controle positivo o único que apresentou a presença de halo opaco circundando as colônias verdeazuladas em 24 e $48 \mathrm{~h}$ resultando em presuntivo positivo para L. monocytogenes. Essa diferenciação e detecção de Listeria spp. ocorre pela ação da enzima $\beta$-D-glicosidase que atua na clivagem dos conjugados X- $\beta$-D-glucosídeo, deixando as colônias com coloração verdeazulada. Porém, L. monocytogenes diferencia-se das demais através da atividade de lecitinase pela ação da fosfatidil inositol fosfolipase C (PIPLC). Desta forma, L. monocytogenes, além de formar colônias verde-azuladas, hidrolisa o substrato do meio produzindo um halo opaco que circunda as colônias (ISO, 2017). No entanto, mesmo não apresentando colônias características de L. monocytogenes, todos os demais testes obrigatórios para L. monocytogenes foram realizados a fim de conhecer a ecologia bacteriana presente.

O teste de hemólise em ágar sangue é positivo para L. monocytogenes quando as colônias são estreitas, claras e apresentam zonas leves de hemólise (ISO, 2017) como encontrado no controle positivo (CP). Duas amostras de queijo apresentaram hemólise fraca (A1 e A5 com Ágar Palcam). A presença de hemólise é o principal fator de virulência de $L$. monocytogenes, porém L. seeligeri e L. ivanovii também apresentam atividade hemolítica (RYSER; DONNELLY, 2015) e, desta forma, as amostras que apresentaram hemólise fraca podem ser quaisquer destas espécies. As demais amostras não apresentaram atividade hemolítica, o que indica que essas possivelmente não são colônias de L. monocytogenes, mas sim de outras espécies do gênero Listeria spp.

$\mathrm{O}$ consumo de carboidratos como xilose e ramnose produzindo ácidos modifica o $\mathrm{pH}$ do meio e ocorre mudança na coloração do mesmo. O uso ou não desses carboidratos depende da espécie de Listeria spp. que está sendo analisada. Listeria monocytogenes, por exemplo, é positiva para consumo de L-Ramnose e negativa para D-Xilose (ISO, 2017) e, portanto, analisando os resultados encontrados nenhuma das amostras apresentou teste positivo para $L$. monocytogenes. As colônias isoladas a partir do ágar Palcam das amostras de queijo A1, A4 e A5 apresentaram consumo de xilose e ramnose positivos. De acordo com a ISO 11290 (2017) dentre as espécies do gênero Listeria spp., L. fleischmanii, L. rocourtiae e $L$. weihenstephanensis são capazes de fermentar L-ramnose e D-xilose produzindo ácido e a 
espécie L. welshimeri é capaz de consumir D-xilose e possui característica de reação variável para o consumo de L-ramnose com produção de ácido. Com isso, as amostras positivas para ambos os carboidratos podem ser quaisquer das espécies citadas acima. Enquanto isso, as colônias isoladas a partir do ágar ALOA e Oxford da amostra A5 apresentaram consumo somente de xilose, característica apresentada pelas espécies $L$. ivanovii, L. seeligeri e variável para L. welshimeri (ISO, 2017). Já as demais amostras não apresentaram consumo de nenhum dos dois carboidratos, característica identificada como L. marthii e variável para L. innocua e L. grayi (ISO, 2017). Desta forma, as amostras apresentaram-se positivas para Listeria spp. mas negativas para L. monocytogenes.

A reação da catalase ocorre quando, ao adicionar-se peróxido de hidrogênio $\left(\mathrm{H}_{2} \mathrm{O}_{2}\right)$ sobre uma colônia de bactéria, a enzima catalase atua degradando o peróxido de hidrogênio em $\mathrm{H}_{2} \mathrm{O}$ e $\frac{1}{2} \mathrm{O}_{2}$, liberando bolhas de oxigênio (TORTORA; FUNKE; CASE, 2012). O teste de reação da catalase resultou para todas as amostras como catalase positiva, característica de Listeria spp. uma vez que estas possuem a enzima catalase (ISO, 2017).

Outra característica que todas as colônias presuntivas de Listeria spp. apresentaram foi a forma de cocobacilo Gram-positivo, confirmando a característica da possível presença de Listeria spp. nas amostras. Já no teste VM-VP as colônias das amostras A4 e A5 isoladas de ágar Palcam, juntamente com o controle apresentaram resultado positivo tanto para VM quanto para VP, característica apresentada por Listeria spp. dentre as quais podemos citar L. seeligeri, L. welshimeri, L. grayi e com característica variável para consumo de glicose mas VP positivo temos L. monocytogenes, $L$. innocua, $L$. ivanovii e $L$. marthii que também podem ser uma das espécies detectadas nessa amostras dependendo da combinação dos resultados das demais análises (NÚÑEZ-MONTERO et al., 2018). Porém a amostra A1 apresentou VM positivo e VP negativo, característica que possivelmente possa inferir na presença de Listeria spp. uma vez que algumas espécies isoladas recentemente apresentaram resultado VP negativo como $L$. rocourtiae, L. weihenstephanensis e L. fleischmanii (ISO, 2017; NÚÑNEZ-MONTERO et al., 2018). As demais amostras apresentaram-se VM e VP negativos, característica não encontrada nos estudos analisados como característica de Listeria spp..

Por sua vez, o teste de redução de nitrato apresenta modificação da coloração do meio para rosa, quando as bactérias não realizam a reação de redução de nitrato à nitrito. Caso as bactérias realizassem essa reação a coloração do meio não sofreria modificação quando adicionado pó de zinco (BRASIL, 2003). As amostras de queijo artesanal apresentaram resultado negativo para todas as colônias isoladas, característica apresentada para as espécies L. monocytogenes, L. innocua, L. seeligeri, L. ivanovii e $L$. marthii, podendo ser variável para diferentes cepas de L. grayi. Desta forma, as colônias isoladas podem ser quaisquer das espécies 
citadas acima, mas não apresentam característica de $L$. rocourtiae, $L$. weihenstephanensis e $L$. fleischmanii uma vez que essas apresentam característica de redução de nitrato positivo (NÚÑEZ-MONTERO et al., 2018).

E por fim, todas as amostras apresentaram teste de motilidade negativo. Listeria spp. apresentam característica de crescimento tipo guarda-chuva, no entanto, algumas espécies de Listeria isoladas recentemente não apresentam motilidade quando realizada análise no ágar motilidade (ISO, 2017). Sendo assim, mesmo não apresentando crescimento tipo guarda-chuva, as colônias isoladas das amostras de queijo tipo artesanal podem ser do gênero Listeria spp.. Isto porque ao analisarmos todos os testes em conjunto encontramos características que confirmam o gênero Listeria spp. como os aspectos microscópicos, a reação positiva para catalase, e adicionalmente VP e motilidade positiva ou negativa (ISO, 2017).

A fim de indicarmos a possível espécie de Listeria spp. presente em cada amostra de queijo, foram comparados os resultados da Tabela 2 com os descritos no anexo D da ISO 112901 de 2017 dos principais testes para identificação de Listeria spp.. As possíveis espécies presentes no queijo artesanal podem ser observadas na Tabela 3.

Tabela 3. Possíveis espécies de Listeria para cada colônia suspeita isolada de queijo artesanal, com base nas características apresentadas na ISO 11290-1 (2017).

\begin{tabular}{ccc}
\hline Amostra & Ágar de isolamento & Possível espécie de Listeria spp. \\
\hline A1 & Palcam & Nenhuma espécie característica \\
A4 & Palcam & L. welshimeri, L. fleischmanii, $L$. rocourtiae ou $L$. \\
& wLOA* & weihenstephanensis \\
& ALOA* & Nenhuma espécie característica \\
A5 & Oxford & L. marthii, L. grayi ou L. innocua \\
& Palcam & L. ivanovii, L. welshimeri ou L. seeligeri \\
& ALOA* & Nenhuma espécie característica \\
A7 & Oxford & L. ivanovii, L. welshimeri ou L. seeligeri \\
& Palcam & L. marthii, L. grayi ou L. innocua \\
& L. marthii, L. grayi ou $L$. innocua \\
\hline
\end{tabular}

A1, A4, A5, A7: amostras de queijo colonial. *Ágar base para ALOA sem suplemento.

Desta forma, podemos constatar que as quatro amostras de queijo que apresentaram resultados presuntivos para Listeria spp. foram confirmadas, apresentando possibilidades de serem diferentes espécies do gênero Listeria spp., com exceção da presença de Listeria monocytogenes, a qual não apresentou confirmação. Estudos realizados por Barancelli et al. (2014) e Oxaran et al. (2017), nos estados de São Paulo e Goiás, demonstram a baixa incidência de L. monocytogenes em indústrias e produtos lácteos incluindo o leite cru utilizado como matéria prima. A presença de Listeria spp. pode estar relacionada não só às condições higiênico-sanitárias do local de produção, mas também à matéria prima utilizada para a produção do alimento (HAMIDIYAN et al., 2018; REES; DOYLE; TAYLOR, 2017), isso 
porque a alimentação do gado leiteiro como o consumo de silagens e a contaminação durante a ordenha têm sido consideradas a maior fonte de Listeria spp. no leite cru.

\section{Conclusões}

Como não houve presença de L. monocytogenes em nenhuma das amostras avaliadas, conclui-se que as amostras de queijo artesanal de leite cru analisadas neste estudo não representam risco para a saúde do consumidor, no que concerne à Listeria monocytogenes, importante patógeno alimentar. Porém, devido à presença do gênero Listeria spp., faz-se importante o constante acompanhamento do rebanho e da produção de queijo artesanal.

\section{Agradecimentos}

Agradecemos à Andréia Tecchio, pela disponibilização de recursos do projeto R4D para a aquisição de materiais de laboratório e pela coleta de amostras junto aos produtores. Agradecemos também à Empresa de Pesquisa Agropecuária e Extensão Rural de Santa Catarina (EPAGRI) pela coleta de amostras e o transporte até o IFC Campus Concórdia e à Cooperativa de Crédito Rural Seara (CrediSeara) pela viabilização da aquisição de materiais de laboratório para a realização das análises.

\section{Referências}

BARANCELLI, Giovana V. et al. Pulsed-Field Gel Electrophoresis characterization of Listeria monocytogenes isolates from cheese manufacturing plants in São Paulo, Brazil. International Journal of Food Microbiology, [S. l.], v. 173, p. 21-29, 2014. Disponível em: https://doi.org/10.1016/j.ijfoodmicro.2013.12.018

BARRÍA, Carla et al. Tracing Listeria monocytogenes contamination in artisanal cheese to the processing environments in cheese producers in southern Chile. Food Microbiology, [S. l.], v. 90, p. 103499, 2020. Disponível em: https://doi.org/10.1016/j.fm.2020.103499

BRASIL. LEI 13.860, DE 18 DE JULHO DE 2019. Dispõe sobre a elaboração e a comercialização de queijos artesanais e dá outras providências.Brasil: Diário Oficial da União, Brasília, 2019.p. 1.

BRASIL. Instrução Normativa n. 62, de 26 de agosto de 2003. Métodos Analíticos Oficiais para Análises Microbiológicas para Controle de Produtos de Origem Animal e Água. Diário Oficial da União. Ministério da Agricultura, Pecuária e Abastecimento, Brasília, DF, 18 set. 2003, Seção 1, p. 14.

CARVALHO, Michelle de Medeiros et al. Traditional Colonial-type cheese from the south of Brazil: A case to support the new Brazilian laws for artisanal cheese production from raw milk. Journal of Dairy Science, [S. l.], v. 102, n. 11, p. 9711-9720, 2019. Disponível em: https://doi.org/10.3168/jds.2019-16373

CORREIA, Vinícius Tadeu da Veiga; ASSIS, Isabella Cristina Lopes de. Queijos artesanais : revisão de literatura. Revista eletrônica Nutri Time, [S. l.], v. 14, p. 8001-8008, 2017. 
DESAI, Rahat Wadhwa; TRIMBLE, Lisa M. Listeria monocytogenes. In: LUI, Dongyou (org.). Handbook of Foodborne Diseases. [S. l.]: CRC Press, 2019. p. 195-206. E-book.

FOX, Edward M.; JIANG, Yujun; GOBIUS, Kari S. Key pathogenic bacteria associated with dairy foods: On-farm ecology and products associated with foodborne pathogen transmission. International Dairy Journal, $[S . \quad$ l. $]$, v. 84, p. 28-35, 2018. Disponível em: https://doi.org/10.1016/j.idairyj.2018.03.013

GÉRARD, Amaury et al. Determination of the growth potential of Listeria monocytogenes in various types of Belgian artisanal cheeses by challenge tests. Food Microbiology, [S. l.], v. 92, p. 103582, 2020. Disponível em: https://doi.org/10.1016/j.fm.2020.103582

HAMIDIYAN, Negar et al. The prevalence of Listeria spp. food contamination in Iran: A systematic review and meta-analysis. [S. l.]: Elsevier Ltd, 2018. Disponível em: https://doi.org/10.1016/j.foodres.2018.02.038

HOFFMANN, S.; SCALLAN, E. Epidemiology, Cost, and Risk Analysis of Foodborne Disease. In: DODD, Christine E. R. et al. (org.). Foodborne Diseases. 3. ed. [S. l.]: Elsevier, 2017. p. 31-63. E-book. Disponível em: https://doi.org/10.1016/B978-0-12-385007-2.00002-4

KAMIMURA, Bruna Akie et al. Large-scale mapping of microbial diversity in artisanal Brazilian cheeses. Food Microbiology, [S. l.], v. 80, p. 40-49, 2019. Disponível em: https://doi.org/10.1016/j.fm.2018.12.014

NÚÑEZ-MONTERO, Kattia et al. Listeria costaricensis sp. nov. International Journal of Systematic and Evolutionary Microbiology, [S. l.], v. 68, n. 3, p. 844-850, 2018. Disponível em: https://doi.org/10.1099/ijsem.0.002596

OMS, Organização Mundial da Saúde. Food-Borne Disease Burden Epidemiology Reference Group. [S. l.: s. n.]. E-book.

OXARAN, Virginie et al. Listeria monocytogenes incidence changes and diversity in some Brazilian dairy industries and retail products. Food Microbiology, [S. l.], v. 68, p. 16-23, 2017. Disponível em: https://doi.org/10.1016/j.fm.2017.06.012

REES, C. E. D.; DOYLE, L.; TAYLOR, C. M. Listeria monocytogenes. In: DODD, Christine E. R. et al. (org.). Foodborne Diseases: Third Edition. 3. ed. [S. l.]: Elsevier Inc., 2017. p. 253-276. E-book. Disponível em: https://doi.org/10.1016/B978-0-12-385007-2.00012-7

RYSER, Elliot T.; DONNELLY, Catherine W. Listeria. In: Compendium of Methods of the Microbiological Examination of Foods. [S. l.]: Washington D.C, 2015. p. 425-443. E-book.

SANTA CATARINA, Governo do Estado. Lei n ${ }^{0} 17486$ de 16 de Janeiro de 2018. Dispõe sobre a produção e comercialização de queijos artesanais de leite cru e adota outras providências. Brasil: Diáro Oficial do Estado, 2018.

SANTA CATARINA, Governo do Estado. Decreto no 362 de 21 de novembro de 2019. Regulamenta a Lei $n^{0} \mathbf{1 7 . 4 8 6}$, de 2018 , que dispõe sobre a produção e comercialização de queijos artesanais de leite cru e adota outras providências.Brasil: Diário Oficial do Estado, 2019. 
SANTOS, Anderson Joaquim Pereira dos. Efeitos do período de maturação de queijos sobre a microbiota deteriorante e listeria monocytogenes. 2016. - Universidade de Brasília, [s. l.], 2016.

THAKUR, Meenakshi; ASRANI, Rajesh Kumar; PATIAL, Vikram. Listeria monocytogenes: A Food-Borne Pathogen. In: HOLBAN, Alina Maria; GRUMEZESCU, Alexandru Mihai (org.). Foodborne Diseases. [S. l.]: Elsevier Inc., 2018. v. 15p. 157-192. E-book. Disponível em: https://doi.org/10.1016/B978-0-12-811444-5.00006-3

TORTORA, Gerard J. ..; FUNKE, Berdell R. ..; CASE, Christie L. Crescimento Microbiano. In: TORTORA, Gerard J. ..; FUNKE, Berdell R. ..; CASE, Christie L. (org.). Microbiologia. 10. ed. [S. l.]: Artmed, 2012. p. 156-183. E-book.

WIWANITKIT, Viroj. Important Emerging and Reemerging Tropical : Food-Borne Diseases. In: HOLBAN, Alina Maria; GRUMEZESCU, Alexandru Mihai (org.). Handbook of Food Bioengineering: FoodBorne Diseases. [S. l.]: Academic Press, 2018. p. 33-55. E-book. 